\title{
Transcultural Adaptation and Validation of the Arabic Version of the Compliance Questionnaire for Rheumatology
}

\section{Nelly Raymond Ziadé ${ }^{1 *}$, Ghada Abi Karam ${ }^{1}$, Nelly Salloum ${ }^{2}$ and Marouan Zoghbi ${ }^{3}$}

${ }^{1}$ Rheumatology Department, Saint-Joseph University, Hotel-Dieu Hospital, Beirut, Lebanon

${ }^{2}$ Registered Nurse, ZClinic, Beirut, Lebanon

${ }^{3}$ Family Medicine Department, Saint-Joseph University, Beirut, Lebanon

*Corresponding Author: Nelly Raymond Ziadé, Rheumatology Department, Saint-Joseph University, Hotel-Dieu Hospital, Beirut, Lebanon.
Received: August 31, 2020

Published: September 25, 2020

(C) All rights are reserved by Nelly Raymond

Ziadé,, et al.

\begin{abstract}
Background: To date, the Compliance Questionnaire for Rheumatology (CQR) is the only self-reported adherence measure created for and validated in Chronic Inflammatory Rheumatic Diseases (CIRDs). However, it has not been validated in Arabic.

Aim: To translate, culturally adapt, and validate the CQR in Arabic.

Methods: Cross-sectional study, with a longitudinal component to test reliability, using the WHO guidelines: forward and backtranslation, cognitive debriefing, and final validation with CIRDs patients (rheumatoid arthritis, spondyloarthritis, connective tissue disease, and Behcet's disease).

Results: The CQR was translated and back-translated by two independent translators, and a cognitive debriefing was performed with 30 patients. For the final validation, 102 patients were included and found that the questionnaire was easy to complete (average time 4.8 minutes). The CQR was significantly associated with self-reported adherence. Test-retest reliability was high (ICC 0.94 (95\% CI 0.85 to 0.98$)$ ), internal consistency was acceptable (Cronbach $\alpha$ of 0.704 ). The mean CQR score was $85.4 \%$ and was statistically associated with age.

Implications: The CQR was validated in Arabic and can be a useful tool in future clinical and research settings in the Arab world.

Keywords: Compliance; Adherence; Questionnaire; Rheumatoid Arthritis; Spondyloarthritis; Connective Tissue Diseases; Behcet's Disease
\end{abstract}

\section{Background}

Adherence to therapy is a significant challenge in chronic inflammatory rheumatic diseases (CIRDs). Although the efficacy of Disease-Modifying Anti-Rheumatic drugs (DMARDs) is well established, many factors such as delayed efficacy, unpleasant side effects, and specific health belief models may prompt patients to stop taking them $[1,2]$. According to the World Health Organization (WHO) report on medication adherence, "increasing the effec- tiveness of adherence interventions may have a far greater impact on the health of the population than any improvement in specific medical treatments" [3].

Suboptimal adherence can lead to disease progression [4], thus increasing the burden on the healthcare system [5]. The apparent treatment "failure" caused by non-adherence can lead to unnecessary treatment escalation resulting in increased costs and decreased quality of life [6]. 
Medication non-adherence in various chronic illnesses, including CIRDs, is typically estimated to be around 30 to $50 \%$ [7-10]. Although physicians tend to agree that adherence is essential, most of them do not systematically measure it during their clinical practice [11]. Moreover, they tend to overestimate it and therefore, they need to use objective assessment tools [12,13].

Many ways of evaluating adherence exist, including direct and indirect measures. Direct measurement of ingestion involves quantifying the concentrations of substances in body fluids. A typical example is dosing serum hydroxychloroquine levels, which correlate with disease activity in systemic lupus erythematosus (SLE) [14]. Biologic assays may seem like the most precise method, but they are not readily available for many drugs; they are expensive and impractical for patients, and their interpretation can be hindered by individual pharmacokinetics. Other direct measurements include direct observation, performed by administering the medication or observing the patient ingesting or auto-administrating it. This method is only practical for single-dose therapies, spaced intermittent administration, or for patients attending infusion centers or hospitals [15]. As for indirect measurements, they are more frequently used and include monitoring pharmacy refills, table counts, the use of electronic devices, and questionnaires [11,12]. Using a validated adherence questionnaire has several advantages over the other methods. It can be done easily without requiring an invasive procedure, is inexpensive, provides relatively accurate measures of true adherence, and can encourage real-life adherence.

To date, the Compliance Questionnaire for Rheumatology (CQR) is the only self-reported adherence measure explicitly created for and validated in rheumatic diseases. It was developed in 1999 in English for patients with rheumatoid arthritis (RA), polymyalgia rheumatica, and gout. This 19-item instrument has encouraging psychometric properties: good test-retest reliability and moderate internal consistency, as per its initial validation using discriminant analyses against an overall patient self-report adherence measure [18]. It was later validated against utilizing electronic medication event monitors (eMEMs), which are currently the gold standard [19]. A shorter version of 5 questions using factor analysis was developed to increase the clinical utility of the questionnaire [20].

In comparison with the Morisky Medication Adherence Scale (MMAS-4), a known generic tool, the CQR appeared to be more sensitive at high levels of adherence [21]. The CQR was validated in French [22], Korean [23], Spanish [24], Italian [25], Turkish [26] and Indian [27] languages.

According to our knowledge, the CQR was never translated or used in Arabic. The Arab world consists of 22 countries in the Middle East and North Africa. Itt includes over 400 million people having a rich diversity of ethnic, linguistic, and religious communities. However, this population shares the same written Arabic language and many cultural similarities [28].

\section{Objectives of the Study}

1. The primary objective of our study was to translate, culturally adapt and validate the CQR in Arabic (a-CQR).

2. The secondary objectives were to estimate the mean a-CQR score in patients with CIRDs and to identify the factors associated with this score.

\section{Methods}

Study design

The study is cross-sectional, with a longitudinal component for test-retest reliability.

We followed the WHO guidelines for the process of translation and adaptation of instruments [29], which consist of four steps:

1. Forward translation, from English to Arabic, by two independent translators (one informed and one uninformed) and synthesis of the translation by an expert panel (two bilingual rheumatologists, one family physician, and one rheumatology nurse).

2. Back-translation, from Arabic to English, and validation by the expert panel of the first Arabic version a-CQR1.0.

3. Field testing and cognitive debriefing by a trained research nurse on a sample of thirty consecutive CIRDs patients, yielding in the a-CQR1.1 version.

4. Final version validation of the a-CQR1.1 with consecutive patients with CIRDs.

\section{Study population}

We included consecutive adult patients with CIRDs (RA, spondyloarthritis ( $\mathrm{SpA}$ ), connective tissue diseases (CTD), and Behcet's disease (BD)) as diagnosed by the rheumatologist, during a routine rheumatology consultation, at two rheumatology clinics. The patients had to be on DMARDs for more than three months and willing to participate in the study. Patients with multiple associated CIRDs 
were excluded. All patients signed an informed consent form before completing the questionnaire.

\section{Study procedures}

Data were collected over three months using a predefined case report form, including demographics, disease characteristics, current disease activity, comorbidities, and concomitant medication. The translated questionnaire (a-CQR1.0) was self-administered, and then the cognitive debriefing interview was conducted by a trained research nurse.

Cognitive debriefing [30] aims to determine if the target population understands the questionnaire in the translated form the same as the original would be understood. Through a face-to-face interview, the nurse asked the patients to restate in their own words what they thought each translated question means. Complicated and confusing questions were identified at this stage, and errors in understanding were recorded for each patient.

Finally, the validation of the final version (a-CQR1.1) and testing of the psychometric properties were performed using a larger sample of patients. The feasibility was determined by the ability and the easiness of completing the questionnaire. The time needed to complete the questionnaire was recorded. The patients were asked to rate their self-estimation of adherence to chronic treatment on a 4-point Likert scale, ranging from very adherent to non-adherent. The validity of the a-CQR1.1 was tested against this self-reported adherence using one-way ANOVA. The test-retest reliability was evaluated at a one-week interval using the intraclass correlation coefficients (ICCs), by repeating the same questionnaire by the study nurse through telephone contact. The internal consistency was assessed using Cronbach $\alpha$.

The score calculation was as follows: each item of the CQR was graded from 1 (don't agree at all) to 4 (agree very much), except for questions $4,8,9,11,12$, and 19 , which were graded inversely. The CQR-19 is the sum of all the grades minus 19, divided by 0.57 (final percentage of adherence). The total score varies from zero to 100 , with a higher score indicating a higher adherence. The CQR-5 is based on questions $2,3,5,6$, and 17 .

The mean a-CQR1.1 score was calculated and compared between the diseases using one-way ANOVA. A score $>=80 \%$ was considered satisfactory, as per previous definitions [19,31-33].

The correlation of the final a-CQR1.1 score with the demographic and clinical data was performed using multiple linear regression. The correlation between a-CQR-19 and a-CQR-5 was performed using the Spearman coefficient.

\section{Statistical considerations}

Considering an adherence of 75\%, a type I error of 0.05 and a type II error of 0.10 , the number needed to include is 38 patients (MedCalc software). We aimed to include around one hundred patients to be consistent with previously published adherence studies and to obtain a balance between the four included diseases. A pvalue $\leq 0.05$ was considered significant. All other statistical analyses were performed using SPSS V25.0.

\section{Results}

Of the 107 consecutive CIRDs patients invited to complete the questionnaire, 102 accepted to participate and were included in the analysis (Patients characteristics in table 1). The five patients who declined stated that they didn't have time to participate. The mean age was 56.3 years (SD 15.1), 75.5\% were female, and $44.1 \%$ had done university studies. The mean disease duration was 8.7 years (SD 8.3). There were $44.1 \%$ of patients with RA, $26.5 \%$ with SpA, 23.5\% with CTD, and 5.9\% with BD.

\begin{tabular}{|c|c|}
\hline Population characteristics & Results \\
\hline $\mathrm{N}$ & 102 \\
\hline Disease, $n(\%)$ & \\
\hline - Rheumatoid Arthritis & $45(44.1 \%)$ \\
\hline - Spondyloarthritis & $27(26.5 \%)$ \\
\hline - Connective Tissue Disease & $24(23.5 \%)$ \\
\hline - Behcet's disease & $6(5.9 \%)$ \\
\hline Mean age in years (SD) & $56.3(15.1)$ \\
\hline Female gender, $\mathrm{N}(\%)$ & $77(75.5 \%)$ \\
\hline Married, N (\%) & $82(80.4 \%)$ \\
\hline University studies, $\mathrm{N}(\%)$ & $45(44.1 \%)$ \\
\hline Employed, N (\%) & $52(51 \%)$ \\
\hline Disease duration, years (SD) & $8.7(8.3)$ \\
\hline Time since diagnosis, years (SD) & $5.3(6.2)$ \\
\hline On conventional DMARDs, $\mathrm{N}(\%)$ & $89(87.3 \%)$ \\
\hline On biologic DMARDs, $\mathrm{N}(\%)$ & $34(33.3 \%)$ \\
\hline On targeted synthetic DMARDs, N (\%) & $11(10.8 \%)$ \\
\hline DAS-28 in RA, mean (SD) & $3.21(1.3)$ \\
\hline Selected Known Comorbidities, N (\%) & \\
\hline - $\quad$ Smoking & $32(31.4 \%)$ \\
\hline - Hypertension & $48(47.1 \%)$ \\
\hline - Dyslipidemia & $30(29.4 \%)$ \\
\hline - Diabetes & $14(13.7 \%)$ \\
\hline - Cancer & $4(3.9 \%)$ \\
\hline - Depression & $26(25.5 \%)$ \\
\hline - $\quad$ COPD/Asthma & $5(4.9 \%)$ \\
\hline - Osteoporosis & $26(25.5 \%)$ \\
\hline Weekly total number of pills, mean (SD) & $40.7(24.8)$ \\
\hline
\end{tabular}

Table 1: Population characteristics. 
Qualitative evaluation

Phase 1 and 2: Forward and back-translation

The expert panel identified translation discordance in the wording of two questions at this step (Questions 4 and 11 in table 2). The discussion between the expert panel and the translators reached a final agreement on the wording, yielding in the first aCQR1.0 version.

Phase 3: Field testing and cognitive debriefing

Thirty consecutive patients were included in phase three, and identified the following questions as confusing (Table 2):

\begin{tabular}{|c|c|c|}
\hline & English (original) & Arabic (translation) \\
\hline Q1 & $\begin{array}{l}\text { If the rheumatologist tells me to take the } \\
\text { medicines, I do so }\end{array}$ & إلأدوية، طلب منَّي طبيب أفعل ذلك اض المقاصل أن أتناول \\
\hline Q2 & $\begin{array}{l}\text { I take my anti-rheumatic medicines because I } \\
\text { then have fewer problems }\end{array}$ & أقلَّ أتناول أدوية الروماتيزمر لأنه سيكون لديّ مشاكل \\
\hline Q3 & $\begin{array}{l}\text { I definitely don't dare to miss my anti- } \\
\text { rheumatic medications }\end{array}$ & بالتأكيد لا أجرؤ على تفويت أدوية الروماتيزم \\
\hline Q4* & $\begin{array}{l}\text { If I can help myself with alternative therapies, } \\
\text { I prefer that to what my rheumatologist } \\
\text { prescribes }\end{array}$ & 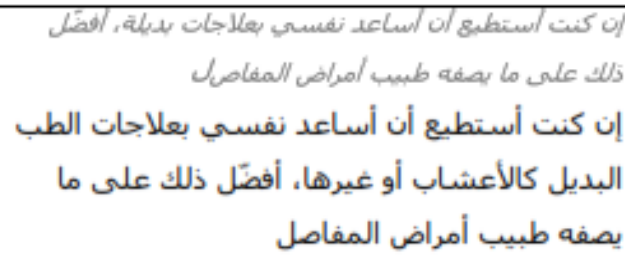 \\
\hline Q5 & $\begin{array}{l}\text { My medicines are always stored in the same } \\
\text { place and that's why I don't forget them }\end{array}$ & أنسماهم تخزين أدويتي دائمًا في المكان نفسه لذلك لا \\
\hline Q6 & $\begin{array}{l}\text { I take my medicines because I have complete } \\
\text { confidence in my rheumatologist }\end{array}$ & ألتاول أدويتَي لأنّبي أثق تمامًا بطبيبي لأمراض \\
\hline Q7 & $\begin{array}{l}\text { The most important reason to take my anti- } \\
\text { rheumatic medicines is that I can still do what } \\
\text { I want to do }\end{array}$ & 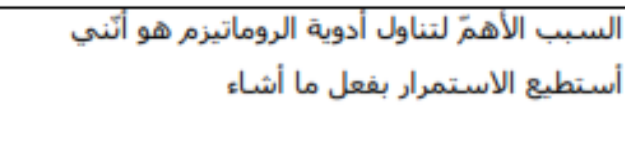 \\
\hline Q8* & $\begin{array}{l}\text { I don't like to take medicine. If I can do } \\
\text { without them, I will }\end{array}$ & الا أحبَ أن أتناول الأدوية، وإن كنت أستطيع \\
\hline Q9* & $\begin{array}{l}\text { When I am on vacation, it sometimes happens } \\
\text { that I don't take my medicines }\end{array}$ & عندما أكون في إجازة، أحيانًا لا أتناول أدويتي \\
\hline Q10 & $\begin{array}{l}\text { I take my anti-rheumatic drugs, for otherwise } \\
\text { what's the point of consulting a } \\
\text { rheumatologist? }\end{array}$ & أمراض التناول أدوية الروماتيزم، وإلاً ما نفع استشارة طيبب \\
\hline $\begin{array}{l}\text { Q11 } \\
*\end{array}$ & $\begin{array}{l}\text { I don't expect miracles from my anti- } \\
\text { rheumatic medicines }\end{array}$ & 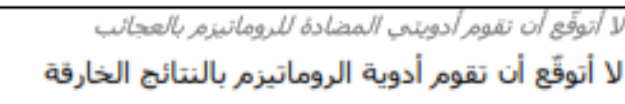 \\
\hline Q12 & $\begin{array}{l}\text { If you can't stand the medicines you might } \\
\text { say: "throw it away, no matter what" }\end{array}$ & 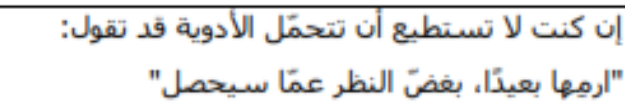 \\
\hline Q13 & $\begin{array}{l}\text { If I don't take my anti-rheumatic medicines } \\
\text { regularly, the inflammation returns }\end{array}$ & إن لم أتناول أدوية الروماتيزمر بانتظام، يعود الالتعاب \\
\hline
\end{tabular}

Table 2: CQR-19 in the original English version and the translated Arabic versions.

*Questions that were found confusing.

The questions from the first version a-CQR1.0 are in grey; the final version a-CQR1.1 is in black. 
- Question 4: The phrase "alternative therapies" was poorly understood as the patient would take an alternative treatment in case the rheumatologist prescribed it.

- Question 8: Was interpreted as a preference for not being sick and, therefore, not having to take any medication.

- Questions 9 and 19 were identified as redundant: This may be because, in our culture, long vacations are not a frequent custom, except for students.

- Question 10: The answer was evidently "yes" since the questionnaire was completed at the rheumatologist's clinic.

- Question 11: The term "miracle" was understood in a religious way of speaking, and it was evident that no miracle could be expected from a simple drug, as miracles are only "the act of God".

- Question 16: Many patients didn't know what the pill organizer was since they were not familiar with this tool in our region.

At the end of this phase, questions 4,11, and 16 were rephrased. The new version, aCQR1.1, was used for the final validation step by the patients.

Quantitative evaluation: validation of the a-CQR1.1 (phase 4)

All the patients (102) participated in the phase:

- Feasibility: The average time to complete the questionnaire was 4 minutes and 48 seconds (SD 41 seconds). The majority of the patients (98\%) stated that the questionnaire was easy to complete.

- Validity: Using their subjective opinion, most of the patients considered themselves as adherent to therapy (88.2\%). The most commonly reported reasons for poor adherence were forgetfulness $(20.6 \%)$, uncertainty about treatment efficacy $(17.6 \%)$, treatment cost $(15.7 \%)$ and fear of side effects (6.9\%).

The validity was estimated in comparison to self-reported adherence. The a-CQR1.1 was significantly lower in the poor adherence group ( $\mathrm{p}=0.014)$.

- Reliability: The test-retest reliability of the a-CQR1.1 was performed at a one-week interval. Agreement between the a-CQR1.1 at time zero and week one was high (ICC = 0.94; range 0.85 to $0.98, \mathrm{p}<0.001$ ).
- Internal consistency: The internal consistency of the aCQR1.1 was calculated, yielding a Cronbach $\alpha$ of 0.704 , which is in the acceptable range.

- $\quad$ Score calculation: The mean a-CQR v1.1 score was $85.4 \%$ (SD 8.2), ranging from $52 \%$ to $100 \%$. Seventy-eight percent of the patients had a satisfactory score (as defined by a threshold of $>=80 \%$ ). In bivariate analysis, the a-CQR1.1 correlated with age (higher in older patients, $p=0.007$ ), gender (higher in females, $p=0.035$ ), disease (higher in RA, $p=0.042$ ), total number of comorbidities ( $\mathrm{p}=0.005$ ), but not with individual comorbidities. On the other hand, it was not correlated with the total number of pills per week, educational level, disease activity, and disease duration. In multivariable analysis, only age remained statistically associated with the a-CQR1.1 score $(\mathrm{p}=0.001)$.

The mean a-CQR-5 score was $98.7 \%$ (SD 3.8), ranging from $85 \%$ to $100 \%$. The correlation between a-CQR-19 and a-CQR-5 was statistically significant ( $p=0.024$ ) but considered low with a Spearman coefficient of 0.369 (lower than the 0.7 acceptable threshold).

\section{Discussion}

We translated, culturally adapted, and validated the Arabic version of the CQR (a-CQR1.1), using the WHO methodology, to provide a useful tool in estimating adherence in the Arab countries. Three questions were rephrased to be better understood in the cultural setting. As in the Korean version [23], question 16 about the pill organizer was rephrased as this tool is not widely used in our region.

The a-CQR1.1 was well accepted among CIRDs patients, quick and easy to perform. The time required to complete was relatively short, even shorter than the timing described in the previous international versions. The a-CQR was shown valid compared to self-reported adherence. The test-retest reliability at one week was high (0.94), higher than the English (0.73) [18], Spanish (0.76) [34] and Korean versions (0.71) [23], which were tested at two-weeks intervals. The internal consistency was acceptable, slightly lower than the Spanish version [34].

Our population showed a high mean level of adherence (aCQR1.1 = 85.4\% (SD 8.2)), as defined by the $80 \%$ cut-off $[18,31$ - 
33]. The mean a-CQR1.1 was slightly higher than the one observed in the English (76.6\% (SD 12.8)) [32], French (75\%) [22], Korean (61.4\% (SD 5.97) [23] and Turkish versions (69.2\%) [26], but was in the same range of the Spanish (79.1\%) [31] and the Indian versions (86.4\%) [27].

Based on the work of de Klerk., et al. who found that the sensitivity of CQR to detect adherence $=<80 \%$ was $62 \%$ [32], we could have an estimation of the real meaning of the CQR in a research setting. For example, we could roughly estimate that a CQR score of $85.4 \%$ reflects a true adherence around 53\%, which corresponds to the published data on adherence in chronic diseases [7-10].

Subjective adherence was also clearly overestimated in our study, with most of the patients subjectively considering themselves as totally or moderately adherent to therapy (97.1\%). This result confirms that this subjective assessment is poorly useful for the realistic estimation of adherence $[12,13]$.

A potential explanation of this high level of reported adherence may be due to answering the questionnaire at the rheumatology clinic, which may influence the patient's responses [12,13]. However, the questionnaire was completed in a separate office. It was not viewed by the rheumatologist at the time of completion, to reduce any doctor's influence.

Self-reported poor adherence was related mainly to forgetfulness (unintentional non-adherence), uncertainty about treatment efficacy (patients' concerns and belief models), and treatment cost, as in the identified factors by WHO [3]. Interestingly in our study, fear of side effects was not a major obstacle to adherence.

The a-CQR1.1 score was higher in RA patients in bivariate analysis. This issue is controverted across studies, with some reports that suggested lower adherence in SLE compared to RA, whereas others found no differences [32,35-38].

In our study, a higher a-CQR1.1 was associated with age, similarly to the literature, with older patients having higher adherence scores $[31,39,40]$. This finding could be explained by the wisdom that patients may acquire with age, which makes them more adherent to the physician's recommendations. We identified some factors associated with a-CQR1.1 in the bivariate analysis only, reflecting the literature: female gender, the number of comorbidities $[31,40]$. We didn't find any association with the class of medication as in other studies [19]. However, the low sample size of our study may have prevented reaching statistical significance.

Many studies found an association between adherence and the relationship with the medical team, the confidence in the rheumatologist, and the medication necessity beliefs [31,40-45]. Although not formally identified by our study, these factors were partially reflected in the "uncertainty about treatment efficacy" stated by our patients as a reason for poor adherence.

Due to the low correlation found between the full version (CQR19) and the short version (CQR-5), with the latter seeming less discriminating and potentially less sensitive to change, the expert panel decided to recommend the full version for the future use. The time to complete the questionnaire in its full version was acceptable, especially that it is used as an auto-questionnaire, which does not take any time from the clinical consultation.

The main limitation of our study is its low sample size. However, our sample size remains consistent with previous validation studies (median number in studies was 41 to 274 patients) [22-26,46]. Also, we didn't test the construct validity of the questionnaire against pharmacy refills or electronic devices as this is not the objective of our study, as we consider that CQR validity is already established. Moreover, drug dispensing in our country is liberal and almost impossible to track with precision.

The CQR may have some disadvantages: it is an indirect measure, the patients may refuse to complete it or over-report their level of adherence. However, despite its limitations, the CQR has many advantages over other adherence-measuring methods. It is simple, quick, acceptable, easy to read and to understand by the patients, and can be administered easily without the help of an investigator. It can also identify areas of poor adherence specific to one patient and improve patient adherence to treatment. Additionally, it may screen poorly adherent patients before inclusion in a clinical trial or, at the individual level, before starting a specific drug. Finally, in the current study, a-CQR1.1 was validated in a representative sample of several CIRDs with a good range of diseases' types and duration.

\section{Conclusion}

CQR-19 was translated, culturally adapted, and validated in Arabic. It showed to be relatively easy to perform by CIRDs patients 
and had a good reliability and an acceptable internal consistency. Therefore, the a-CQR1.1 could be considered as a useful tool in future clinical and research settings in the Arab world.

\section{Bibliography}

1. Goodacre LJ and Goodacre JA. "Factors influencing the beliefs of patients with rheumatoid arthritis regarding disease-modifying medication". Rheumatology 43 (2004): 583-586.

2. Harrold LR and Andrade SE. "Medication Adherence of Patients with Selected Rheumatic Conditions: A Systematic Review of the Literature". Seminars in Arthritis and Rheumatism 38 (2009): 396-402.

3. World Health Organization. "Adherence to Long-Term Therapies" (2003).

4. Grijalva CG., et al. "Assessment of Adherence to and Persistence on Disease-Modifying Antirheumatic Drugs (DMARDs) in Patients With Rheumatoid Arthritis". Medical Care 45 (2007): S66-S76.

5. Roter DL and Hall JA. "Strategies for enhancing patient adherence to medical recommendations". The Journal of the American Medical Association 271 (1994): 80.

6. Hughes DA., et al. "The impact of non-compliance on the costeffectiveness of pharmaceuticals: A review of the literature". Health Economics 10 (2001): 601-615.

7. Steiner JF and Prochazka AV. "The assessment of refill compliance using pharmacy records: Methods, validity, and applications". Journal of Clinical Epidemiology 50 (1997): 105-116.

8. Barber N. "Patients' problems with new medication for chronic conditions". Quality and Safety in Health Care 13 (2004): 172-175.

9. Viller F., et al. "Compliance to drug treatment of patients with rheumatoid arthritis: a 3 year longitudinal study". The Journal of Rheumatology 26 (1999): 2114-2122.

10. Park DC., et al. "Medication adherence in rheumatoid arthritis patients: older is wiser". Journal of the American Geriatrics Society 47 (1999): 172-183.

11. Hobeika M., et al. "Adherence to systemic therapies for immune- mediated inflammatory diseases in Lebanon : a physicians ' survey from three medical specialties". Patient Preference and Adherence (2017): 939-945.
12. Copher R., et al. "Physician perception of patient adherence compared to patient adherence of osteoporosis medications from pharmacy claims". Current Medical Research and Opinion 26 (2010): 777-785.

13. JR Curtis., et al. "Agreement between Rheumatologist and Patient-Reported Adherence to Methotrexate in a U.S. Rheumatoid Arthritis Registry". The Journal of Rheumatology 43 (2016): 1027-1029.

14. Geraldino-Pardilla., et al. "Association between hydroxychloroquine levels and disease activity in a predominantly Hispanic systemic lupus erythematosus cohort". Lupus 28 (2019): 862867.

15. Marengo MF., et al. "Improving treatment adherence in patients with rheumatoid arthritis: what are the options?" International Journal of Clinical Rheumatology 10 (2015): 345-356.

16. Chisholm MA., et al. "Patient factors associated with adherence to immunosuppressant therapy in renal transplant recipients". American Journal of Health-System Pharmacy 62 (2005): 17751781.

17. Hill J. "Adherence with drug therapy in the rheumatic diseases Part two: measuring and improving adherence". Musculoskeletal Care 3 (2005): 143-156.

18. De Klerk E., et al. "Development of a questionnaire to investigate patient compliance with antirheumatic drug therapy". The Journal of Rheumatology 26 (1999): 2635-2641.

19. De Klerk E., et al. "Patient compliance in rheumatoid arthritis, polymyalgia rheumatica, and gout. Erratum appears in". The Journal of Rheumatology 30.2 (2003): 423.

20. Hughes LD., et al. "A 5 item version of the Compliance Questionnaire for Rheumatology (CQR5) successfully identifies low adherence to DMARDs". BMC Musculoskeletal Disorders 14 (2013): 286.

21. Pedersini R., et al. "Validation Of The Compliance-Questionnaire-Rheumatology, A Behavior-Focused Predictive Adherence Questionnaire, With The Morisky Medication Adherence Scale". Value Heal 17 (2014): A50.

22. Choquette D., et al. "Prediction of non-adherence in patients with rheumatoid arthritis Data comparison between 0 and 6 months". Annals of the Rheumatic Diseases 74 (2015): 245. 
23. Lee JY., et al. "Cultural Adaptation of a Compliance Questionnaire for Patients with Rheumatoid Arthritis to a Korean Version". The Korean Journal of Internal Medicine 26 (2011): 28.

24. Fernández-Avila D., et al. "Initial Validation of ComplianceQuestionnaire- Rheumatology (CQR) In Patients with Rheumatoid Arthritis in Bogot'A, Colombia". Annals of the Rheumatic Diseases 74 (2015): 974-975.

25. Ometto F., et al. "Adherence in rheumatoid arthritis patients assessed with a validated Italian version of the 5-item Compliance Questionnaire for Rheumatology". Clinical and Experimental Rheumatology 37 (2019): 915-922.

26. Cinar FI., et al. "Cross-Cultural Adaptation, Reliability, and Validity of the Turkish Version of the Compliance Questionnaire on Rheumatology in Patients With Behçet's Disease". Journal of Transcultural Nursing 27 (2016): 480-486.

27. Shetty R., et al. "Impact of Medication Adherence by Using Indian Version Compliance Questionnaire Rheumatology (Cqr) and Medication Adherence Report Scale (Mars) Tools on Quality of Life of Patients With Rheumatoid Arthritis". Value Health 17 (2014): A385.

28. Chardin J. Arab World (2004).

29. World Health Organization Process of translation and adaptation of instruments (2014).

30. Language Scientific Cognitive Debriefing Explained (2017).

31. Marras C., et al. "Identification of patients at risk of non-adherence to oral antirheumatic drugs in rheumatoid arthritis using the Compliance Questionnaire in Rheumatology: an ARCO sub-study". Rheumatology International 37 (2017): 1195-1202.

32. De Klerk E., et al. "The Compliance-Questionnaire-Rheumatology Compared with Electronic Medication Event Monitoring: A Validation Study". The Journal of Rheumatology 30 (2003): 2469-2475.

33. Rauscher V., et al. "High degree of nonadherence to diseasemodifying antirheumatic drugs in patients with rheumatoid arthritis". The Journal of Rheumatology 42 (2015): 386-390.

34. Salgado E., et al. "Spanish transcultural adaptation and validation of the English version of the compliance questionnaire in rheumatology". Rheumatology International 38 (2018): 467472 .
35. Mehat P., et al. "Medication Nonadherence in Systemic Lupus Erythematosus: A Systematic Review". Arthritis Care and Research 69 (2017): 1706-1713.

36. Arturi P., et al. "Adherence to treatment in patients with ankylosing spondylitis". Clinical Rheumatology 32 (2013): 10071015.

37. Hromadkova L., et al. "Drug compliance in patients with systemic scleroderma”. Clinical Rheumatology 31 (2012): 15771583.

38. Garcia-Gonzalez A., et al. "Treatment adherence in patients with rheumatoid arthritis and systemic lupus erythematosus". Clinical Rheumatology 27 (2008): 883-889.

39. Wabe N., et al. "Factors associated with medication adherence in a longitudinal study of rheumatoid arthritis patients". International Journal of Clinical Practice 73 (2019): 1-9.

40. Salaffi F., et al. "Adherence to subcutaneous anti-TNF $\alpha$ agents in patients with rheumatoid arthritis is largely influenced by pain and skin sensations at the injection site". International Journal of Rheumatic Diseases (2020): 1-8.

41. Kelly A., et al. "Patients' Attitudes and Experiences of DiseaseModifying Antirheumatic Drugs in Rheumatoid Arthritis and Spondyloarthritis: A Qualitative Synthesis". Arthritis Care and Research 70 (2018): 525-532.

42. Raghunath S., et al. "Qualitative assessment of medication adherence in patients with rheumatic diseases on biologic therapy". Clinical Rheumatology 38 (2019): 2699-2707.

43. Zayed HS., et al. "Evaluation of treatment adherence in patients with Behçet's disease: its relation to disease manifestations, patients' beliefs about medications, and quality of life". Clinical Rheumatology 38 (2019): 761-768.

44. Zwikker HE., et al. "Perceived need to take medication is associated with medication non-adherence in patients with rheumatoid arthritis". Patient Preference and Adherence 8 (2014): 1635-1645.

45. Pasma A., et al. "Facilitators and barriers to adherence in the initiation phase of disease-modifying antirheumatic drug (DMARD) use in patients with arthritis who recently started their first DMARD treatment". The Journal of Rheumatology 42 (2015): 379-385. 
46. Salgado E., et al. "Spanish transcultural adaptation and validation of the English version of the compliance questionnaire in rheumatology". Rheumatology International 38 (2018): 467-

472 .

\section{Assets from publication with us}

- Prompt Acknowledgement after receiving the article

- Thorough Double blinded peer review

- Rapid Publication

- Issue of Publication Certificate

- High visibility of your Published work

Website: https://www.actascientific.com/

Submit Article: https://www.actascientific.com/submission.php

Email us: editor@actascientific.com

Contact us: +919182824667 